\title{
A novel method for closure of a persistent gastrostomy feeding site fistula
}

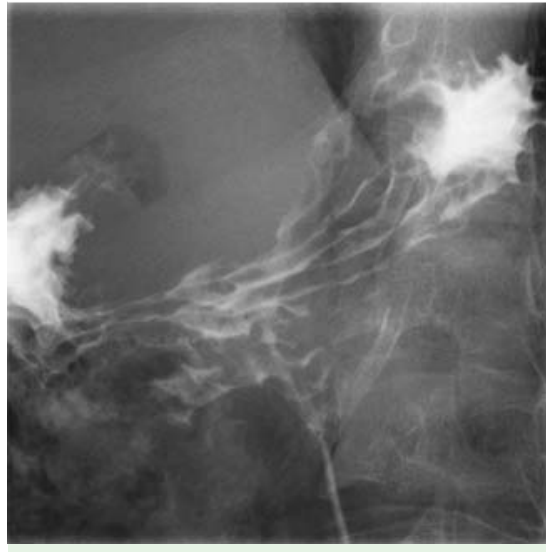

Fig. 1 Contrast study of a persistent gastrostomy site fistula in a 22-year-old man presenting with leaking gastric contents 24 months after the removal of a gastrostomy.

A 22-year-old man with congenital intestinal malrotation and autoimmune enterocolitis, previously requiring enteral nutritional support for many years, presented with persistently leaking gastric contents 24 months after the removal of a gastrostomy. Attempted closure with three endoscopic clips at the internal opening 8 months earlier had been unsuccessful.

A contrast study confirmed persistent fistula with a short tract ( $\bullet$ Fig. 1 ). While the patient was under general anesthesia, a further procedure was performed comprising closure with silver nitrate cauterization and a $10-\mathrm{mm}$ hexagonal nitinol clip (Padlock-G Clip; Aponos Medical, Kingston, New Hampshire, USA). The internal opening was identified endoscopically $(\bullet$ Fig.2a). The external opening was infiltrated with $7 \mathrm{~mL}$ of $1 \%$ lignocaine as a local anesthetic. The tract just allowed passage of a 3-mm-diameter silver nitrate (75\% w/w) stick for cauterization, with the depth confirmed endoscopically ( $\bullet$ Fig.2b). The inner opening and surrounding tissue were drawn into a deployment pod attached to a standard esophagogastroduodenoscope (Olympus, Tokyo, Japan) ( Fig.2c). The $10-\mathrm{mm}$ hexagonal nitinol clip with six inner prongs was then deployed over this pod, with good im-
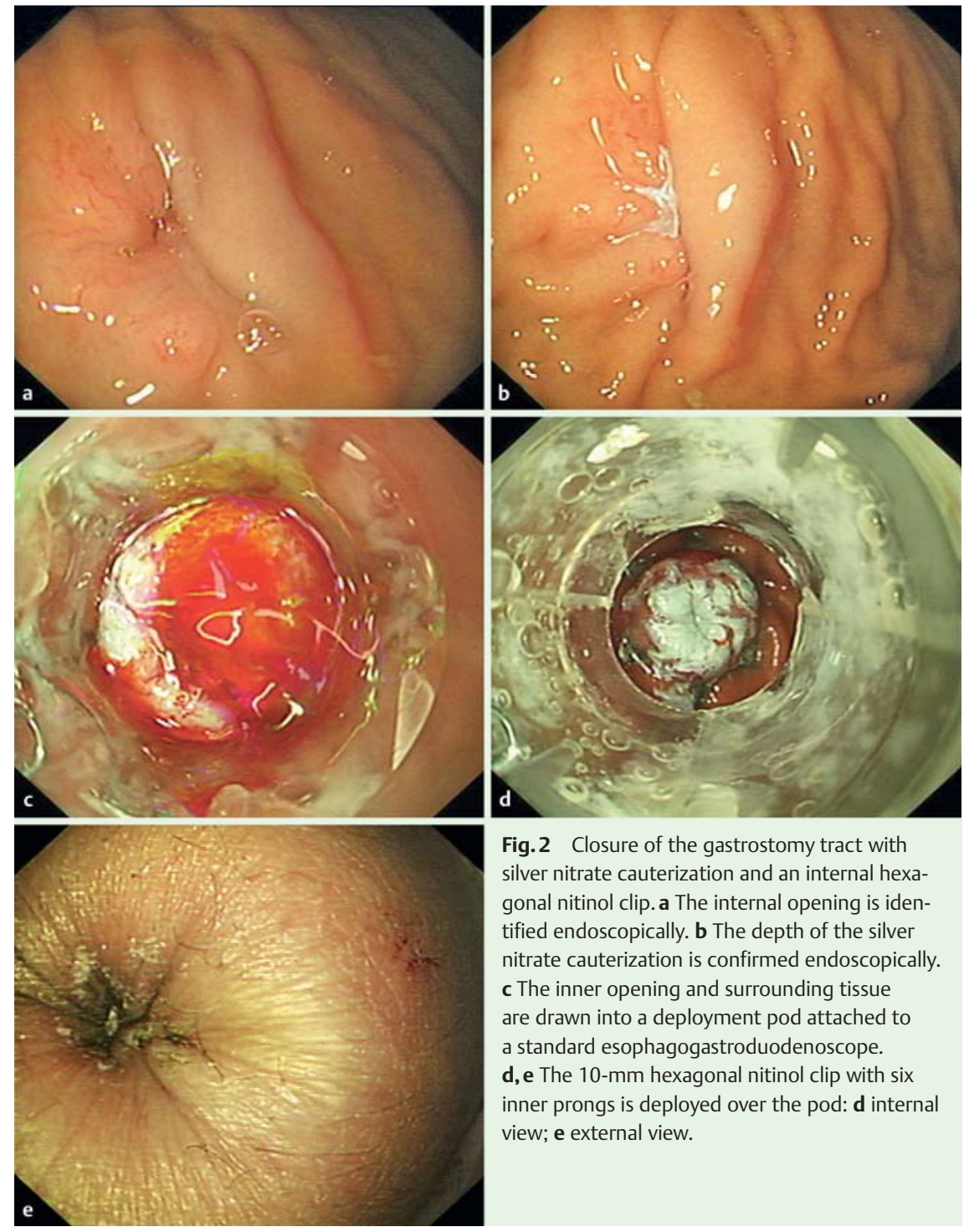

Fig.2 Closure of the gastrostomy tract with silver nitrate cauterization and an internal hexagonal nitinol clip. a The internal opening is identified endoscopically. $\mathbf{b}$ The depth of the silver nitrate cauterization is confirmed endoscopically. c The inner opening and surrounding tissue are drawn into a deployment pod attached to a standard esophagogastroduodenoscope. d, e The 10-mm hexagonal nitinol clip with six inner prongs is deployed over the pod: $\mathbf{d}$ internal view; e external view.

mediate effect ( $\bullet$ Fig. 2 d, $\bullet$ Fig. 2 e). The patient reported mild, self-limiting discomfort at the site for 3 days after the procedure, but there was no persistent drainage or abdominal pain at follow-up at 6 months.

Persistence of a gastrocutaneous fistula, defined as the leakage of gastric contents for at least 1 month after the removal of a gastrostomy tube, occurs in up to $34 \%$ of patients [1]. Previously, surgical closure was required, but more recently, multiple endoscopic methods with varying efficacy have been described. These include chemical or electrical cauterization in combination with clip closure [2], endoscopic suturing [3], fibrin glue placement [4], and over-the-scope clip placement [5]. This is the first report to describe the use of a 10-mm hexagonal nitinol clip in combination with silver nitrate cauterization as an effective option for the closure of persistent gastrocutaneous fistula at a gastrostomy site. Apart from causing transient discomfort, the method appears to be safe. 


\section{Endoscopy_UCTN_Code_TTT_1AO_2AI}

\section{Competing interests: None}

\section{Mayur Garg', Ana Wilson ${ }^{1,2}$, Simon Gabe ${ }^{2,3}$, Brian P. Saunders ${ }^{1,2}$, Siwan Thomas-Gibson ${ }^{1,2}$}

${ }^{1}$ Wolfson Unit for Endoscopy, St. Mark's Hospital, Watford Road, Harrow, Middlesex, United Kingdom

2 Imperial College, London, United Kingdom

${ }^{3}$ Lennard-Jones Intestinal Failure Unit, St. Mark's Hospital, Watford Road, Harrow, Middlesex, United Kingdom

\section{References}

1 Janik TA, Hendrickson RJ, Janik JS et al. Analysis of factors affecting the spontaneous closure of a gastrocutaneous fistula. J Pediatr Surg 2004; 39: 1197-1199

2 Teitelbaum JE, Gorcey SA, Fox VL. Combined endoscopic cautery and clip closure of chronic gastrocutaneous fistulas. Gastrointest Endosc 2005; 62: 432 - 435

3 Eskaros S, Ghevariya V, Krishnaiah $M$ et al. Percutaneous endoscopic suturing: an effective treatment for gastrocutaneous fistula. Gastrointest Endosc 2009; 70: 768-771

4 Gonzalez-Ojeda A, Avalos-GonzalezJ, MucinoHernandez MI et al. Fibrin glue as adjuvant treatment for gastrocutaneous fistula after gastrostomy tube removal. Endoscopy 2004; 36: 337-341

5 Singhal S, Changela K, Culliford A et al. Endoscopic closure of persistent gastrocutaneous fistulae, after percutaneous endoscopic gastrostomy (PEG) tube placement, using the over-the-scope-clip system. Ther Adv Gastroenterol 2015; 8: $182-188$

\section{Bibliography}

Dol http://dx.doi.org/

10.1055/s-0034-1393588

Endoscopy 2015; 47: E629-E630

(c) Georg Thieme Verlag KG

Stuttgart · New York

ISSN 0013-726X

\section{Corresponding author}

\section{Siwan Thomas-Gibson, MD}

Wolfson Unit for Endoscopy

St. Mark's Hospital

Watford Road

Harrow, UK HA13U]

United Kingdom

Fax: + 44-208-423-3588

s.thomas-gibson@nhs.net 